Due November 9: Dr Mathew White at the following email address mwhite@stpeters.sa.edu.au

Tom Brunzell is a PhD Candidate at the University of Melbourne Graduate School of Education, Centre of Positive Psychology and Youth Research Centre. Co-Founder of the KIPP Infinity School in Harlem, New York City, he is now Senior Advisor Education, Berry Street Childhood Institute, Victoria, Australia. tbrunzell@berrystreet.org.au

\title{
Healing and Growth in the Classroom: A Positive Education for Trauma-Affected and Disengaging Students
}

I count myself among educators and researchers for whom positive education offers both a catalytic re-visioning of the purpose of education, and a positive disruption to the business-as-usual approach to academic learning. Our intent is to promote and embed a positive education that addresses the differentiated abilities and learning-readiness of all students. Within schools and school networks for disadvantaged students, I have witnessed remarkable progress including best practice implementation of positive education (Seligman et al., 2009; Waters, 2011) and co-designed initiatives like the Character Growth Card (KIPP, 2014).

We have just begun. We are far from narrowing the achievement gap for vulnerable students. The Australian context for our research is startling: one in four children achieves below national benchmarks for education attainment (Lamb et al., 2015). I believe positive education must play a role in redesigning curriculum and school culture to nurture durable education outcomes for disadvantaged students. That advance relies on teachers' access to guidance about effectively implementing the potentially confusing array of positive education school interventions.

Trauma affects student outcomes. Although there is limited international data regarding trauma frequency and student achievement, we know that up to 40 per cent of all students in the United States are compromised by the impacts of trauma and chronic stressors (National Child Traumatic Stress Network, 2005). To address their needs, positive education needs to be woven into trauma-informed approaches. Together with Professor Lea Waters $(\mathrm{PhD})$ and Dr Helen Stokes (PhD), I have developed the trauma-informed positive education (TIPE) approach (Brunzell, Stokes, \& Waters, 2015). This mode is being tested through research at the Melbourne Graduate School of Education, University of Melbourne. Preliminary evidence from schools working with our TIPE approach shows that teachers have enlarged 
their understanding about the developmental needs of children whose lives are compromised by trauma resulting from family and community destabilisation (Brunzell, Stokes, \& Waters, in press).

This chapter describes our research in positive education and comments on early data from classroom interventions with trauma-affected students. It concludes with recommendations for future research about the extent to which positive education can meet the healing and growth needs of trauma-affected students. My colleagues and I believe that when teachers are assisted to respond to the unmet needs of their most vulnerable students, then classrooms are better prepared to realise the academic and wellbeing goals of all students.

\section{Motivating Students to Learn about Wellbeing}

Our research investigates teachers working with students on the margins of their school communities. One teacher reflects this concern:

Learning how resilient people think; developing a growth mindset; discovering character strengths? My students desperately need these skills—but they won't engage or see the importance of these lessons.

She represents the voices of many teachers desperately trying to meet complex cognitive, affective, and physical needs of students whose classroom experiences include various states of dysregulation and stress, and who appear unwilling to learn.

However, we are yet to fully understand how to effectively implement and apply positive education with struggling students. A central puzzle for teachers revolves around student motivation and what educators in our research call student 'willingness'. They constantly revisit the conundrum posed by those students who lack intrinsic motivation to learn for the sake of learning, or to learn for the sake of reaching new thresholds on their academic journey. Educators ask what they can do to harness these students' motivation for wellbeing learning.

Certainly, student motivation scholarship remains a pillar of education research (see, for example, Deci, Koestner, \& Ryan, 1999). For struggling or disengaging students, the motivation to persevere with academic learning and successfully complete secondary school can seem beyond reach. Maintaining motivation takes on new significance when it comes to 
teaching wellbeing which lifts the floorboards of student identity. Wellbeing learning asks for increased levels of reflection, meta-cognition, and social skills, all of which intrude on one's identity more than learning academic content. Many who work in this field sit side-by-side with teachers wrestling with, and even successfully juggling, classroom management, school discipline procedures, restorative practices, and the like. Yet still they struggle to teach wellbeing to their students who most need it.

\section{Trauma-affected Classrooms}

Our research investigates dysregulated students in the context of childhood trauma. Students were identified as trauma-affected by schools based upon interactions with child protective services, school mental health and wellbeing teams, and teacher assessments of learning readiness indicated by self-regulation and relational capacities. When traumatic events occur for children (for example, home destabilisation, family violence, unexpected loss of a loved one, substance abuse within a family), repeated triggering of the stress response may lead to a resetting of the individual baseline for stress response activation. Affected children come to see the world as no longer good and safe. That can turn classroom learning into a series of obstacles they fail or reject.

Neuropsychologist Allen Schore proposes that trauma compromises emotional and thinking abilities which can seriously impede the capacities that learning requires (Schore, 2012). I argue here that many current positive education interventions require a strong ability to confidently think and reflect (for example, understanding the connection between thoughts and feelings, identifying a fixed versus growth mindset, strategically planning effective personal goals, or reflecting on one's character strengths).

The trauma-informed pedagogical literature clearly shows two domains of teacher practice enable learning and thinking readiness. The first domain is healing self-regulatory abilities achieved through focusing on regulating both emotional and physical responses to stress. The second is healing relational capacities that forge the strong bonds necessary to buffer potential classroom stressors. Positive education, reframed through a traumatology lens, is what constitutes TIPE—a considered, developmental approach (Brunzell et al., 2015).

In response to the first of these domains, TIPE encourages teachers to consider building strong self-regulation as the first task in their classrooms. Effective classrooms are 
hubs of micro-routines and predictable processes. Teachers must reflect on inconsistency, and on occasions when classroom routines are challenged by students who resist them. Teachers can consider positive ways to reinforce self-regulation and integrate the body through rhythmic games, active brainbreaks, mindfulness and other opportunities that help students de-escalate and self-regulate.

In response to the second domain, teachers must be positive templates for healthy relationships in the lives of students who may not understand that a teacher's job is to support, connect, and challenge students to step outside their comfort zone to learn. When faced with classroom challenge, teachers must demonstrate healthy relationships as stable models for containing anxiety and stress. This requires deep work within individual teachers so they can confidently offer models of de-escalation, attachment, attunement and relational co-regulation.

TIPE takes teachers on this journey. First they are shown the importance of classrooms that reinforce predictability, rhythm, and self-regulatory interventions. Then they are assisted to build sturdy classroom relationships which buffer the stressors of learning. Finally, we encourage teachers to explicitly model and teach skills requiring strong thinking ability: transforming fixed mindsets to growth mindsets, practicing resilient self-talk, and building on character strengths.

\section{Working Closely with Teachers}

Our research follows teachers who teach positive education, using the TIPE approach, to disadvantaged and trauma-affected students in Victoria, Australia. Employing an appreciative inquiry action research methodology (Ludema \& Fry, 2008) the early data is promising: trauma-affected students learned and understood their own routes to de-escalation and to self-regulation. Teachers reported their ability to strengthen classroom relationships with struggling students. Subsequently, their students were then prepared for, and embraced, wellbeing lessons that required significant self-reflection and strategy practice. Further, teachers have nurtured their own growth mindsets to maintain their own empowered identities in the face of common classroom stressors.

Following these teachers and their classroom journeys has allowed us to better understand how to link student motivation and wellbeing through strengthening connections between intrigue (the hook), motivation (the will), ability (the capacity to engage), and the 
student's understandings of the effectiveness of their own learning. This quote illustrates one teacher's moment of realisation:

It's confronting to think, 'Maybe I'm the barrier here!' As teachers we believe in wellbeing, but this motivational piece of getting students to learn about themselves-it's like a hidden curriculum that you're not told about in teacher training. If I don't understand how to hook my students into wellbeing and my classroom doesn't have the right management, it's not going to work; and more damaging, turn them off to this [positive education] learning.

Early work with teachers suggests effective teachers who apply the TIPE model to themselves record greater shifts in classroom teaching and student management. In this sense, the sequence of interventions is for everyone in the classroom - students and the adults who instruct them every day. This illustrates the strong connective relationship between teacher and student - and the teacher's new understanding that within positive education, both teacher and student are linked in an interactive exchange of learning, modelling, and reflection. We now plan to harness these newfound learnings to inspire teachers to persevere on the toughest of days when students' misguided attempts to meet their unmet needs escalate into defiance.

\section{Future Directions}

Research with trauma-affected and dysregulated students presents methodological and ethical challenges that constrain progress in our field. However, these challenges are countered by the values underpinning this research: when a teacher can reach the student who struggles most, then all students will recognise the relevance of positive education and its potent application to successful daily relationships and classroom learning. If our positive education research demonstrates significantly improved outcomes for vulnerable students, then our new pedagogy and paradigm can make incredible contributions to educational attainment across a range of school settings.

Further investigation should incorporate young people's voices, revealing their understandings of motivation, effectiveness, and application. Might we need to rename concepts so they are more relevant to the complexity of students' lives? Can students cocreate a wellbeing curriculum more relevant to their daily strategies and long term planning? 
My colleagues and I are repositioning positive education. For our most vulnerable students, I have asserted the potential of positive education using TIPE's developmental approach. I have suggested directions arising from our early research focused on disadvantage and struggling students. We believe TIPE's developmental approach can enable schools to effectively differentiate support so students can meet these learning aims and connect to themselves, their teachers, and their school communities.

\section{References}

Brunzell, T., Stokes H., \& Waters, L. (2015). Trauma-Informed Positive Education: Using Positive Psychology to Strengthen Vulnerable Students. Contemporary School Psychology, 1-21. DOI 10.1007/s40688-0150070-x

Deci, E. L., Koestner, R., \& Ryan, R. M. (1999). A meta-analytic review of experiments examining the effects of extrinsic rewards on intrinsic motivation. Psychological Bulletin, 125(6), 627.

KIPP. (2014). Character Growth Card. Retrieved from http://www.kipp.org/files/dmfile/January2014CharacterGrowthCard.pdf

Lamb, S., Jackson, J., Walstab, A. \& Huo, S. (2015). Educational opportunity in Australia 2015: Who succeeds and who misses out. Centre for International Research on Education Systems, Victoria University for the Mitchell Institute. Melbourne: Mitchell Institute.

Ludema, J.D., \& Fry, R.E. (2008). The practice of appreciative inquiry. In P. Reason \& H. Bradbury (Eds.), Handbook of Action Research (2 $2^{\text {nd }}$ ed., pp. 280-296). London: Sage Publications, Ltd.

National Child Traumatic Stress Network. (2005). Empirically Supported Treatments and Promising Practices. Los Angeles, CA \& Durham, NC: Author. Retrieved on March 10, 2014, from http://www.nctsnet.org/resources/topics/treatments-that-work/promising-practices

Schore, A.N. (2012). The Science of the Art of Psychotherapy. New York: W.W. Norton \& Company.

Seligman, M.E.P., Ernst, R. M., Gillham, J., Reivich, K., \& Linkins, M. (2009). Positive education: Positive psychology and classroom interventions. Oxford Review of Education, 35, 293-311.

Waters, L. (2011). A review of school-based positive psychology interventions. The Australian Educational and Developmental Psychologist, 28, 2, 75-90. 


\section{University Library}

\section{- M I I N E R VA \\ A gateway to Melbourne's research publications}

Minerva Access is the Institutional Repository of The University of Melbourne

Author/s:

Brunzell, $T$

Title:

Healing and growth in the classroom: A positive education for trauma-affected and disengaging students

Date:

2017-06-16

Citation:

Brunzell, T. (2017). Healing and growth in the classroom: A positive education for traumaaffected and disengaging students. White, MA (Ed.). Slemp, G (Ed.). Murray, AS (Ed.). Future Directions in Well-Being: Education, Organizations and Policy, Future Directions in Well-Being - Education, Organizations and Policy, (1), pp.21-25. Springer International Publishing.

Persistent Link:

http://hdl.handle.net/11343/292025 